\title{
Assessing the Effectiveness of Comic- Style Illustrations for Promoting Environmental Sustainability
}

\author{
Ario B. C Oladumiye E. B Ibiwoye T. I \\ Department of Industrial Design, Federal University of Technology, Akure, Ondo State, Nigeria
}

\begin{abstract}
Environment and lives are interconnected. The environment is currently faced with many challenges such as climate change, which has been due to effects of harmful human activities on the environment. In order to stay alive and healthy, the environment has to be properly cared for, as such, activities causing environmental degradation are to be drastically reduced. This study adopted a pamphlet design as a visual communication tool in order to address and increase awareness on environmental issues, using comic-style illustration to educate the public. Additionally, assessments were made on the effectiveness of the visual design created. Primary data were collected through structured questionnaire administered to a sample of 323 respondents which were randomly selected within business district in Akure. Questionnaire were administered to elicit data on the effectiveness of the design created which were analyzed using Chi-square. The result of the findings revealed that there were positive changes in the disposal habit of the people.
\end{abstract}

Keywords:Graphic Design, Sustainability, Visual Communication, Environment, Wastes Disposal, Indiscriminate waste disposal, Illustration.

Publication date:September $30^{\text {th }} 2020$

DOI: $10.7176 / \mathrm{ADS} / 85-02$

\subsection{Introduction}

Graphic design involves the juxtaposition of words, images, symbols that communicates the designers' intent to viewers through visuals and has helped the society to grow into a highly complex and multicultural one (Oladumiye and Adelabu, 2011). The human environment is surrounded with graphic designs ranging from signs to posters, printed materials to non-printed materials and product design to packaged products. These designs are creatively rendered in order to please, beautify, communicate with and provoke some forms of reactions or actions from people. Since inception, man has always looked for ways to beautify and sustain his environment and the role of graphic design cannot be ignored and overlooked in achieving this vital task.

However, graphic design has gone beyond just creating designs and products. It has a role to play in shaping the environment, hence contributing to its sustainability or otherwise. Michael (2015) specified that sustainability is the dynamic equilibrium in the interaction between a population and its interacting environment without compromising each other. Sustainability is multi-dimensional and one of its major aspect is environmental sustainability (Giovannoni and Fabietti, 2014). Environmental sustainability is however multifaceted and a part is the disposal of waste. As the news on environmental sustainability are spreading around the world, people are becoming aware of the effect of environmental degradation on the earth. Brundtland (1987) stated that the earth is one but the world is different, thus our lives and the lives of other living things around us is being sustained under one biosphere in earth. The factors in the environment work together in order to create a healthy environment by promoting a sustainable environment without having adverse effect on population consisting of humans, lands, plants and animals.

Sadly, graphic designers and design educators in developing countries like Nigeria have continued to ignore environmental issues especially in practice (Stoknes, 2015; Deniz, 2016). This has partially led to the continuous degrading of the environment through unhealthy human activities such as improper waste disposal. Often, graphic designers create appealing products with compelling messages which eventually become acceptable to the populace. In order to create a sustainable environment, graphic designers have a role to play as they serve as the intermediary between clients and the consumers and their responsibility is becoming more important in creating designs with less negative impact as well as proffering solutions to the earth's problems (Deniz, 2016). However, there is a growing recognition of the contributions of art and design to finding creative solutions for global challenges (Wilson, 2010). Visual communication can play major roles in shaping the sustainability of the environment. On the other hand, to communicate efficiently to people about matters relating to the environment using graphic design, visual communication is recognized to be more effective. It has been studied that humans have different types of learning abilities and the human brain is competent in understanding more visually inclined images rather than words (Lydia, 2001). Hence, communication technique need to adjust to the changing condition of the environment by understanding how visuals can be used to tackle environmental problems. Hence, there is the need for graphic designers, especially in developing countries, to adopt graphic designs not just as a means for creating products and aesthetics, but also as a tool for solving issues ranging from social, economic to environmental problems 


\subsection{Literature Review}

\subsection{Emotion and Perception in Design Effectiveness}

Graphic design is a means of communicating to a target audience while communicating with design means having the deep understanding of the person with whom the design is communicating to (Norman, 1988). For a design to be effective, the designer have to understand how to effectively communicate by understanding the human psychology in relations to behavior, attitude, motivation and aspiration. Perception and psychology play an important role in how the human mind sees and processes messages (Aleksandar, 2015). Therefore, understanding the human psychological and perception aspect will enable the designer to create design that will appeal to the emotions of the users on both emotional and intellectual levels, enabling users react positively to the design communicated.

\subsection{Visual communication design}

When creating designs that are visually inclined, the aim is to have an influence on the user's attitude and knowledge. Design is a way to understand communication and an approach for investigating the social world from the standpoint of communication (Aakhus, 2007). One of the most important aspect and purpose of communication is understanding the users, how the message could be presented and medium to convey such message. A good communication design tell stories that remains in the user's heart, hence, Aakhus (2007) pointed that communication design is not a series of convention people follow but an understanding that people employ to devise strategies and practices to engage meaning, action, and coherence. In this line, Daniel (2012) while communicating to public on design for social change employed; Confront controversy, Identify the community's strength, Design with the community voice and Give community ownership as a strategy to influence individual behavior. Thus, if visuals can be incorporated strategically, environmental messages can be transformed into powerful communication tools to support successful community-led initiatives (Zeynep, 2015). As such, every designs intended to communicate to the public arises as a result of having a message or information for users. Visual communication is the action of conceiving, programming and projecting aimed at broadcasting specific messages to specific sectors of the public (Jorge, 2004). "The emergence of visual communication creates the premise for adopting a pictorial, rather than textual view of the world and even literature studies have been forced to conclude that the "world-as-a-text" has been replaced by the "world-as-apicture"” (Lydia, 2001). Glaringly, the power of visual communication can be felt in modern communication such as social media as visual contents are shared with more views. However, (Zeynep, 2015) stated that some visuals may result in misinterpretation and misperception due to various communication design, therefore, visuals may be used to pass the designer's intention to the user but might not create the intended perception among the users.

\subsection{Environmental Awareness Creation}

Considering the environmental degradation and the desire for man to continue living on planet earth as there is no favorable planet that supports human existence has given rise to creating awareness concerning the environment. Ruksana (2017) stated that environmental awareness is carried out in order to help individuals and social group to gain various knowledge and experiences needed in order to acquire basic understanding relating to the environment and its associated issues. Different awareness has been created in different countries since the World Commission on Environment and Development introduced and increased the concept of environmental sustainability. With this awareness creation, a lot of people have come to realize environmental issues. Unfortunately, Ajayi (2016) opined that earth's degradation is far from just being knowledgeable about the environmental problem as its pristinity is consistently and irreversibly being eroded by no less than anthropocentric activities. However, Jubilee (2008) findings indicated that those who have high environmental awareness develop positive attitude towards the environment, thus with the increase in the awareness of environmental issues, a positive attitude towards the environment can be developed. Unfortunately, there are still some set of people who with knowledge of the environment issues still ignore and continue with activities that can lead to more damage.

Considering the way we use our environment and the impacts that are gradually unleashing themselves, there is need to create awareness by addressing the environmental issues and this can be achieved by understanding the causes and the implications. In attaining a sustainable environment, environmental awareness is very important and unless solutions are created, then there might not be anything left on earth for the coming generations.

2.3.1 Tools Used for Environmental Awareness Communication

Due to the environmental concern and human need to solve and reduce the impact on the environment, humans have used different visual communication tools in addressing the public. The traditional media and the new media has been used to play important role in communicating environmental problems by spreading awareness among the people. Otinga (2015) listed four major types of media frequently used for environmental awareness 
creation, which are:

a) Television (Animations, films, news)

b) Radio (Jingles)

c) Books (Newspaper, Fliers, magazine)

d) Internet (Internet enabled mobile phones and computers)

\subsection{Methodology}

Akure is the largest city and capital of Ondo state which is made up of Akure South and Akure North local government and has a population of 491,033 (Ondo State Bureau of Statistics, 2019). This research adopted the practice-led design and survey research. The study adopted the practice-led design to create and explore the effectiveness of graphical designs that could be used to curb the negative habit of improper municipal waste disposal and the survey design method to evaluate the effectiveness of the design created to promote environmental-friendly behavior. Data used were collected through administered questionnaires. The study relied on primary data collected in some selected locations within Akure south and Akure North. Secondary source were gotten from relevant information on related literature in order to supplement data gotten from the field. The sources included thesis, journals, articles from the internet and libraries. Purposive sampling involving selecting samples based on the researcher's judgement was used to select business centers within the study area while random sampling technique was adopted for the purpose of sampling the residents in the business areas. 323 respondents were sampled within the business districts of the study area.

Research Questions

1. What visual communication tool may be used in creating effective environmental awareness?

2. How may the design created to promote environmental-friendly behaviour influence the users?

Research Aim and Objectives

The aim of the study is to increase awareness on the management of waste disposal with view to promoting environmental sustainability.

1. create visual communication design to promote environmental-friendly behaviour on municipal solid waste disposal; and

2. evaluate the effectiveness of the design created to promote environmental-friendly behaviour.

\subsection{Result, Analysis and Discussion}

This paper serve as a further study for an earlier paper on comic-style illustration which involved illustrations using comic-style to depict the various indiscriminate ways of waste disposal within the municipal (Ario et al, 2020). It further depicted the effect it could have on human lives as well as the environment, thus encouraging sustainable practices that could help reduce the impact of such act in the environment. The illustrations created were however creatively arranged and presented in a pamphlet as a visual communication tool for the populace. The visual design created was not subject to the designer's opinion but was validated using expert judgement and test to determine if the design is properly created taking the principles and the element of design into consideration and without creating room for ambiguity among the users. Since the design is in a booklet, then it is assumed that there will be willingness among the users to pick it up and read at any time and frequently.

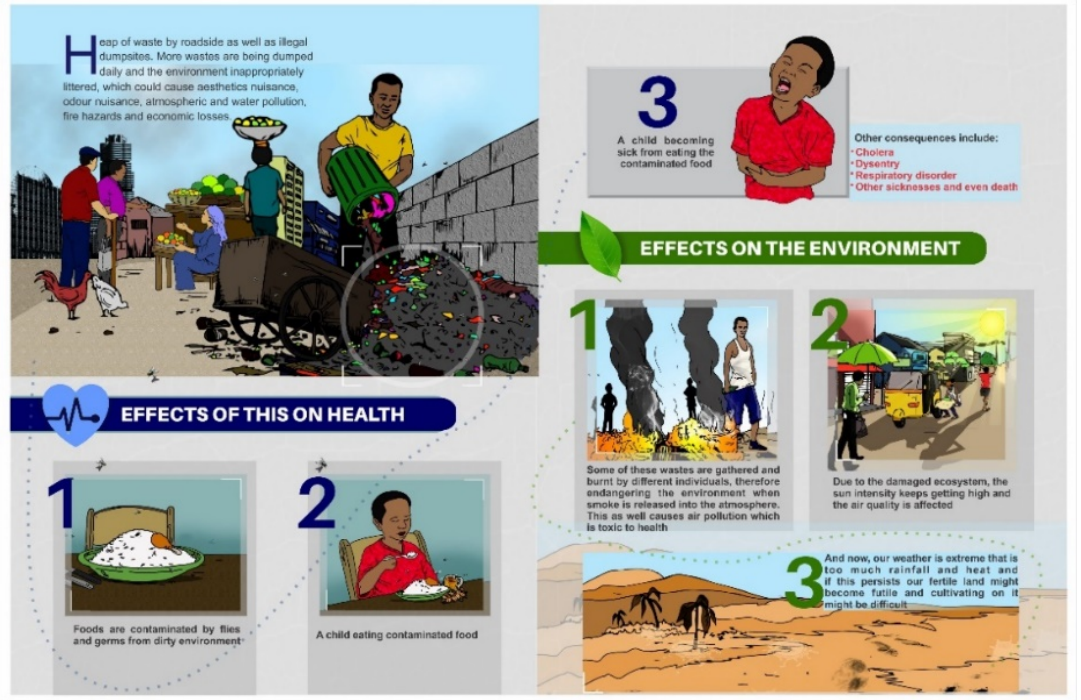

Figure 1: Inner page of design

Source: Ario, Blessing Chidubem (2019) 
The inner page of the pamphlet design described anthropogenic activities and the effect of such action on health which could result to sicknesses. It also labelled the effect climate change, could have on the environment such as global warming, drought, flood, desertification which could affect human daily activities and source of livelihood.

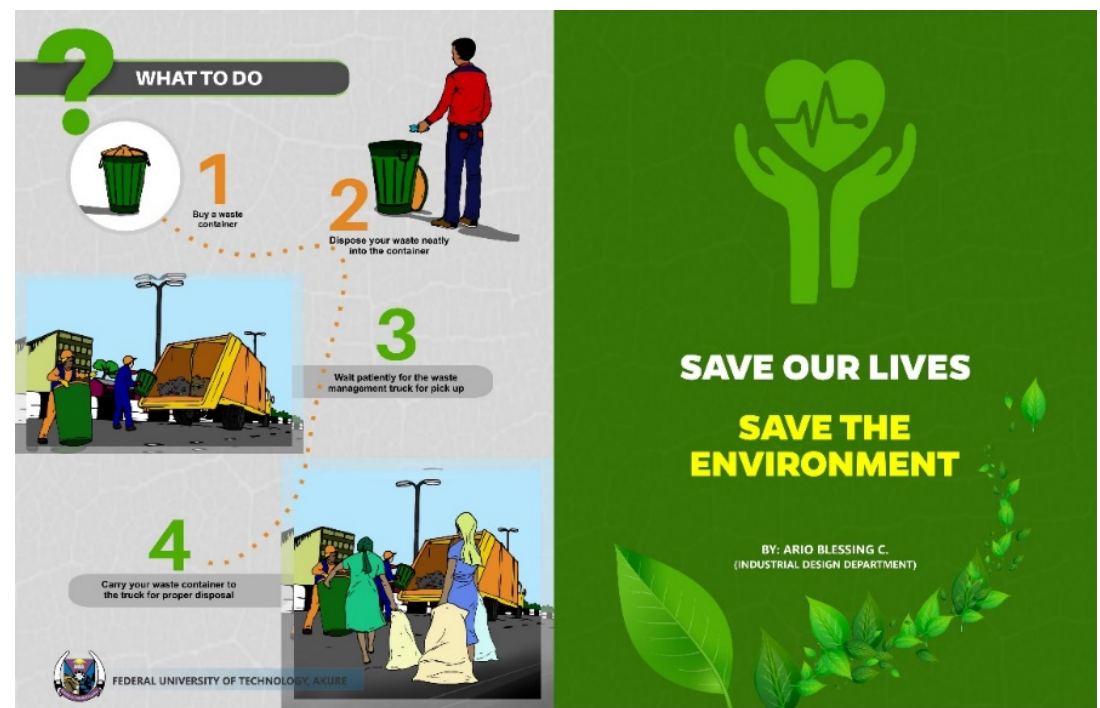

Figure 2: Outer page of design

Source: Ario, Blessing Chidubem (2019)

On the left side is the continuation of the story in the inner page of the design, and this section describes sustainable practices individuals should carry out in order to promote a healthy environment. The sustainable practices on the pamphlet design followed a process which is to acquire a waste container, dispose waste properly into the container, wait for the arrival of the waste collection truck and finally, carry the waste neatly to the waste collection truck for disposal.

The right side of the design addresses the reason for the design which is to "save our lives, save the environment". Our lives and the environment goes hand in hand, to save our lives, there is a need to save the environment because an unhealthy environment can lead to loss of property, death of some inhabitants of the environment and also compromise the future of the unborn generation.

Expert Judgment Evaluation

The data entry software Statistical Package for Social Sciences (SPSS) was used for the data entry and was also used for the analysis. This section targeted a total of 4 questionnaires and were completed representing a retrieval (response) rate of $100 \%$. Result of the design evaluation using frequency table and percentages are as presented in the Table below:

Table 1. Evaluators Perception on Design Created

\begin{tabular}{|l|l|l|l|l|l|l|l|l|l|l|}
\hline \multirow{2}{*}{ Evaluation Criteria } & Excellent & \multicolumn{2}{l|}{ Good } & \multicolumn{2}{l|}{ Fair } & \multicolumn{2}{l|}{ Poor } & $\begin{array}{l}\text { Mean } \\
\text { Score }\end{array}$ & $\begin{array}{l}\text { Inferences } \\
\text { based on mean } \\
\text { class }\end{array}$ \\
\cline { 2 - 10 } & Freg & $\%$ & Freq & $\%$ & Freq & $\%$ & Freq & $\%$ & & \\
\hline $\begin{array}{l}\text { Coverage of subject } \\
\text { matter }\end{array}$ & 1 & $25 \%$ & 3 & $75 \%$ & - & & - & $0 \%$ & 3.3 & Good \\
\hline $\begin{array}{l}\text { Organization of content } \\
\text { for effective } \\
\text { communication }\end{array}$ & 2 & $50 \%$ & 2 & $50 \%$ & - & $0 \%$ & - & $0 \%$ & 3.5 & Excellent \\
\hline Choice of illustration & 3 & $75 \%$ & 1 & $25 \%$ & - & $0 \%$ & - & $0 \%$ & 3.8 & Excellent \\
\hline Legibility & 3 & $75 \%$ & 1 & $25 \%$ & - & $0 \%$ & - & $0 \%$ & 3.8 & Excellent \\
\hline Colour choice & 2 & $50 \%$ & 2 & $50 \%$ & - & $0 \%$ & - & $0 \%$ & 3.5 & Excellent \\
\hline Clarity of message & 1 & $25 \%$ & 3 & $75 \%$ & - & $0 \%$ & - & $0 \%$ & 3.3 & Good \\
\hline \\
Grand Mean
\end{tabular}

Source: Ario, Blessing Chidubem (2019)

The expert judgement on the visual environmental design created are positive with a grand mean score of 3.5. Drawing inference from the class boundary of mean as shown in Table 1, the evaluators agreed that the coverage of subject matter is good with mean score of 3.3. On organization of content for effective communication, the evaluators gave an excellent score with 3.5 mean score. The choice of illustration was excellent with a mean score of 3.8. The table also indicated that the legibility of the design was excellent with a 
mean score of 3.8 and colour choice was also excellent with a mean score of 3.5 while clarity of message was good with a mean score of 3.3. The evaluators showed a positive judgement towards the environmental visual design because their responses was majorly between excellent and good for promoting awareness on the environment.

Therefore, this indicated that the visual design was credible enough to be administered to the communities for awareness creation.

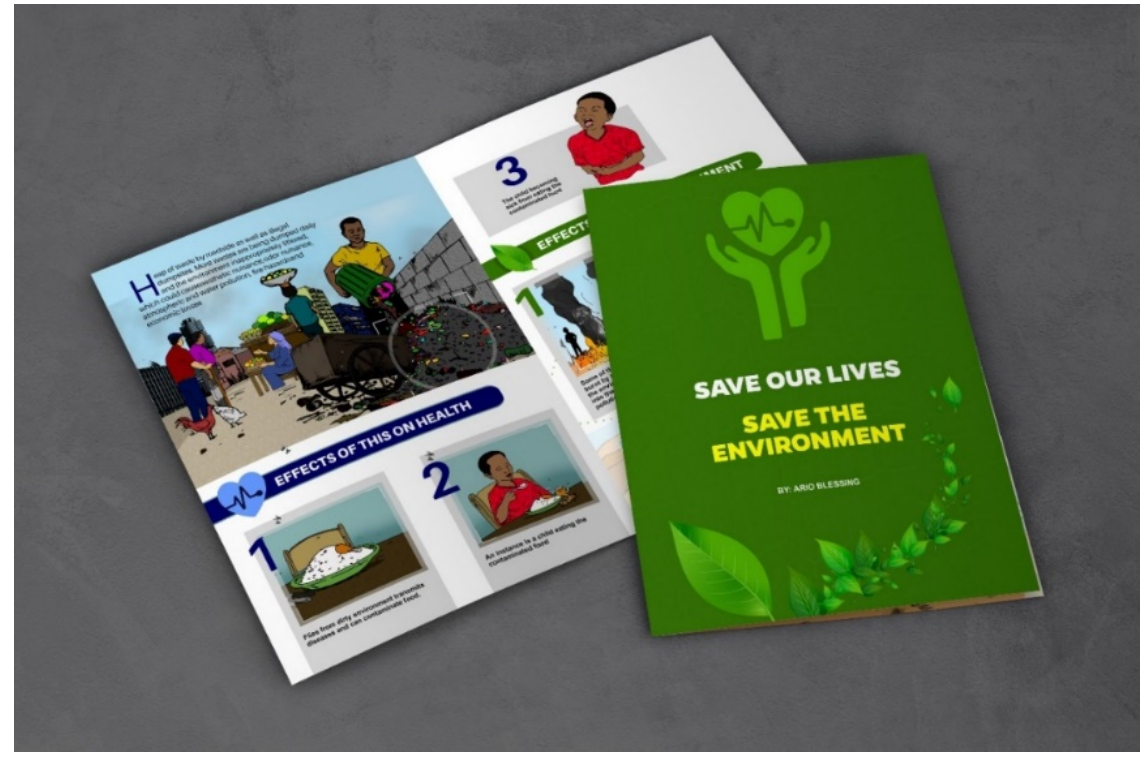

Figure 3: Mockup of design

Source: Ario, Blessing Chidubem (2019)

\subsection{Effectiveness of Visual Design Created}

The data entry software SPSS was used for the data entry and was also used for the analysis. Three hundred and twenty three (323) visual design created were administered hence, the study targeted a total of 323 questionnaires, however, 256 questionnaires were administered and this was due to the absence of the other respondents who were administered the environmental visual design. The questionnaires were administered two weeks after the introduction of the visual design. All the 256 questionnaires were returned which represents a retrieval (response) rate of $100 \%$ required for this study. Results of effectiveness of design created are presented using frequency tables, percentages, mean score and bar chart.

Table 2. Initial method used for disposing waste

\begin{tabular}{lll}
\hline Method & Frequency & Percentage \\
\hline Burning & 28 & 10.9 \\
Dumpsites & 21 & 8.2 \\
Waste management agency & 129 & 50.4 \\
Road sides dumping & 72 & 28.1 \\
Drainages & 6 & 2.3 \\
\hline Total & 256 & 100.0 \\
\hline
\end{tabular}

Source: Ario, Blessing Chidubem (2019)

The initial method used for disposing waste among the respondents is presented in Table 2. The results from this study revealed that 28 respondents representing $10.9 \%$ dispose their waste by burning. Also, the result showed that 21 respondents representing 8.2\% dispose their wastes using dumpsites. 129 respondents representing $50.4 \%$ dispose their waste by using waste management agency, 72 respondents representing 28.1 dumps their wastes by road sides while 6 of the sampled population representing 2.3 dispose their wastes in drainages.

Table 3. Method currently used to dispose waste

\begin{tabular}{lll}
\hline Method & Frequency & Percentage \\
\hline Burning & 11 & 4.3 \\
Dumpsites & 24 & 9.4 \\
Waste management agency & 179 & 69.9 \\
Road sides dumping & 42 & 16.4 \\
\hline Total & 256 & 100.0 \\
\hline
\end{tabular}

Source: Ario, Blessing Chidubem (2019) 
The current method used for disposing waste among the respondents is presented in Table 3 and the results indicated that 11 respondents representing 4.3\% dispose their waste by burning. The result revealed that 24 respondents representing 9.4\% dispose their wastes using dumpsites. 179 respondents representing $69.9 \%$ dispose their waste by using waste management agency, while 42 of the sampled population representing $16.4 \%$ indulge in road sides dumping to dispose their wastes.

From the above results of Table 2 and 3 respectively, it is revealed that 28 respondents representing $10.9 \%$ disposing their waste by burning dropped down to 11 respondents representing 4.3\%, 129 respondents representing 50.4\% disposing their wastes using the waste management agency increased to 179 respondents representing $69.9 \%$. However, 21 respondents representing $8.2 \%$ disposing wastes in dumpsites increased to 24 respondents representing $9.4 \%$ while the 6 respondents representing $2.3 \%$ disposing wastes in drainages stopped it totally.

The analysis implies that there is a little change in the disposal method after the introduction of the design which has influenced the attitude of the users positively even though the difference might not be significance.

Figure 4. Bar chart representation of the effectiveness of design created

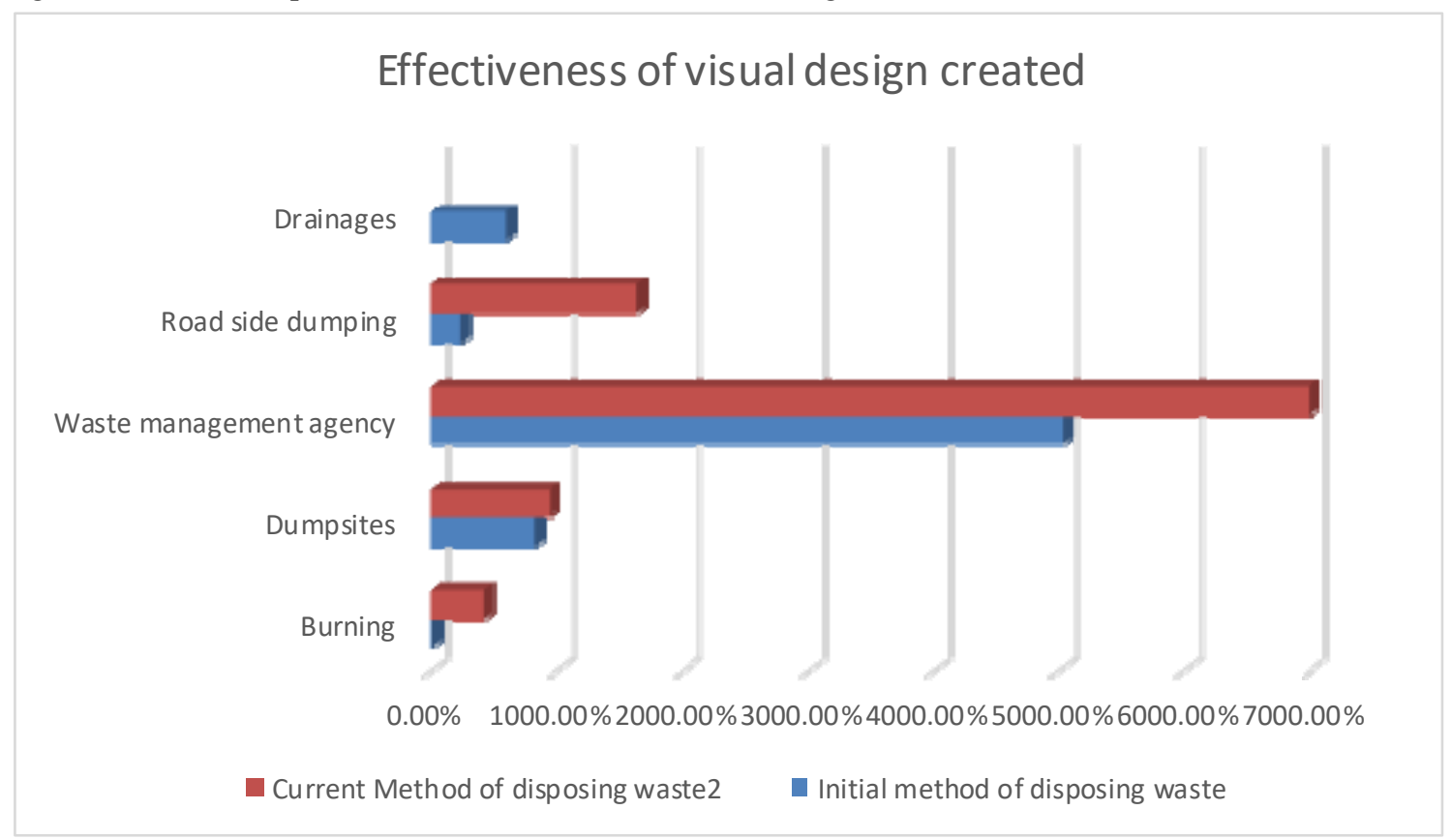

Source: Ario, Blessing Chidubem (2019)

Data in Fig 4 represents Table 2 and Table 3 which presents a side by side comparison of data gotten from the field for easier understanding. The blue bar represents the initial method used in disposing waste among residents while the brown bar represents the current method adopted for waste disposal.

Table 4. Evaluating the effectiveness of the visual design created

\begin{tabular}{|c|c|c|c|c|c|c|c|c|c|c|c|c|}
\hline Effectiveness & Highly effec & tive & Effective & & Indifferent & & Non Effect & & $\begin{array}{l}\text { Highly Non } \\
\text { Effective }\end{array}$ & & $\begin{array}{l}\text { total } \\
\text { frequency }\end{array}$ & $\begin{array}{l}\text { Mean } \\
\text { score }\end{array}$ \\
\hline & Frequency & Percent & Frequency & Percent & Frequency & Percent & frequency & percent & frequency & percent & & \\
\hline PV & 168 & 65.6 & 86 & 33.6 & 2 & 0.8 & 0 & 0 & 0 & 0 & 256 & 4.65 \\
\hline Time & 45 & 17.6 & 92 & 35.9 & 107 & 41.8 & 10 & 3.9 & 2 & 0.8 & 256 & 3.66 \\
\hline Cost & 163 & 63.7 & 93 & 36.3 & 0 & 0 & 0 & 0 & 0 & 0 & 256 & 4.64 \\
\hline Assimilation & 157 & 61.3 & 99 & 38.7 & 0 & 0 & 0 & 0 & 0 & 0 & 256 & 4.61 \\
\hline Information & 182 & 71.1 & 74 & 28.9 & 0 & 0 & 0 & 0 & 0 & 0 & 256 & 4.71 \\
\hline Clean Env & 62 & 24.2 & 88 & 34.4 & 87 & 34 & 17 & 6.6 & 2 & 0.8 & 256 & 3.75 \\
\hline ATID & 66 & 25.8 & 132 & 51.6 & 15 & 5.9 & 17 & 6.6 & 26 & 10.2 & 256 & 3.76 \\
\hline
\end{tabular}

Source: Ario, Blessing Chidubem (2019)

In Table 4, which shows the effectiveness of the visual design created, the effectiveness of the design created is positive with a grand mean score of 4.25 . The respondents indicated that the present design (PV) tool is highly effective with the mean score of 4.65. This is because the design comes handy and looking at the illustrations, they could relate and understand the message which has been broken down compared to the framing of news aired on television and radio. Otinga (2014) supported the foregoing stating that the complexity of 
languages used by lack of how to break down the environmental matter clearer makes it difficult for residents understanding on such matter.

The time effectiveness (Time) indicated that the respondents agreed that the design is effective with a mean score of 3.66. However, majority indicated that they are indifferent about the time and it was observed that when in their business places, they are mostly particular about their business and might not have the luxury of time to constantly pick up the design to read.

On cost effectiveness (Cost), the design was also revealed to be highly effective with a mean score of 4.64. This could be linked with the fact that the design was brought to them in their comfort zone and without having to wait for electricity before reading the content of the message or having to fuel their respective power generating machines in order to hear the environmental news. And so with this, the design is not cost effective.

Assimilation effectiveness (Assimilation) indicated that majority of the respondents agreed that the design highly effective with a mean score of 4.61. This implies that the design was well understood and knowledge gained can be shared among others. This can therefore be linked to their positive change in attitude towards their disposal habit. Noha (2017) and Tobias (2016) buttressed the findings that visual aids help assimilation among young and old when oral word seems to be difficult to understand.

The table also revealed on effective information (information) that the information passed was highly effective with a mean score of 4.71. This indicates that the respondents were able to update their understanding about environmental issues as well as realized the negative impact indiscriminate disposal could have on lives.

The respondents however revealed that design on clean environment (Clean Env.) effectiveness was effective with a mean score of 3.75 , although there was only $1 \%$ different from those who indicated that they are indifferent about clean environment. This revealed that no matter the message passed across, some people nevertheless are of the opinion that anybody can still choose to discriminate the environment which can be associated to behaviour cankerworm. However with more awareness creation, this believe and mind set might be altered.

Finally, on effective attitude towards indiscriminate dumping (ATID), respondents revealed it to be effective with a mean score of 3.76. This indicates that the design was able to influence their disposal culture.

Based on observation, often times, passers-by engaged in discriminating the environment by littering the environment but with continuous awareness creation, there should be more environmentally conscious behaviour. Yet, the results indicated that the environmental design was able to pass the intended message across to the users and can be linked to Tobias (2016) who confirmed there is a great potential of communication using comic illustrations approach, hence increasing environmental consciousness. By this, both old and young people can easily interpret the message with the aid of illustrated images.

\subsection{Conclusion}

Improper management of waste in the environment has increased environmental degradation amongst other degrading activities humans in third world countries indulge in, with Nigeria as no exception. Environmental issues faced today is no news to a lot of people as well as the different environmental awareness raised as supported by Olabode, William and Kim (2019).

As it is, depletion of the ozone layer causing intense hot weather and other variations in climate, however, this is not only due to the improper disposal of waste but other unsustainable environmental actions. The future of the upcoming generations is compromised and with further degrading activities, then what will the future hold? Hence, the society need to work hand in hand in order to sustain the environment by living sustainably such as engaging in activities that protects the physical environment. This can be achieved by indulging in sustainable practices and ensuring that our lifestyle does not harm other people or deprive the future generations of their ability to a great life.

What can Designers do to Promote a Sustainable Environment?

Graphic designers are great asset to promoting a sustainable environment due to their communication skills with the aid of design tools, thus take responsibility in pioneering different sustainable behavior and eco-friendly products. Nicos (2017) attested that professional practice should avoid creating excessive and useless products, thus developing a product with short life span should be discouraged and emphasis should be placed on promoting products that could be sustainable in such that could be re-used and re-cycled. Although, lot of designers are after aesthetics but this is where the social responsibility sets in for the purpose of sustaining the environment. Other contributions can be towards one's community by promoting sustainable practices through creating designs for the purpose of educating the society and advocate for reduction of human-made impact on the environment and the ecosystem.

This paper hence contributing to knowledge in design for social change, by discussing environmental issues using comic-style illustrations and sustainable practices was proffered. From the findings of the study, the use of graphic design as a means of visually communicating to people by increasing environmental awareness is effective in which when such awareness are continuously raised, people will develop an environmental friendly 
behavior towards the environment.

\subsection{Recommendation}

1. Designers should render services to humanity by using their power and tool as designers to increase awareness on the environment.

2. The researcher recommends that more awareness be created using illustration comics on behavior change and environmental programs be introduced to children at their early stage of education in order to inculcate environmental friendly behavior and open their minds to sense of community responsibility for environments.

\section{References}

Aakhus M. (2007). Communication as Design. Communication Monographs. ISSN 0363-7751. 74 (1). https://doi.org/10.1080/03637750701196383

Ajayi, C., Etuki, E., and Usang, N. (2016). From Environmental Awareness to Environmental Responsibility: Towards a Stewardship Curriculum. Journal of Educational Issues. ISSN 2377-2263. 2(2). https://doi.org/xxx10.5296/jei.v2i2.9265

Aleksandar, D. (2015). Typography in Advertising. Tomas Bata University, Zlín.

Ario, B. C., Oladumiye, E. B., \& Ibiwoye, T. I. (2020). Adopting Comic- Style Illustrations for Promoting Environmental Sustainability. International Journal of Innovative Research and Development, 9(3), 5-13 http://52.172.159.94/index.php/ijird_ojs/article/view/151624.

Brundtland Report (1987). World Commission on Environment and Development (WCED), OurCommon Future. Oxford University Press, Oxford.

Daniel, S. (2012). Designing for Social Change. Social responsibility and the graphic designer. K3, Malmö högskola.

Deniz, D. (2016). Sustainability Thinking and Environmental Awareness through Design Education. Procedia Environmental Sciences, Elsevier B.V, Turkey. 34(1) 70-79.

Giovannoni, E. and Fabietti, G. (2014). What Is Sustainability? A Review of the Concept and Its Applications. Integrated Reporting, Springer International Publishing, Switzerland. https://doi.org/10.1007/978-3-31902168-3 2

Jorge, F. (2004). Communication Design: Principles, Methods, and Practice. Published by Allworth Press. An imprint of Allworth Communications, Inc. 10 East 23rd Street, New York, NY 100101

Jubilee, P. (2008). Environmental Awareness and Environmental Attitude of secondary School Teachers of Maldives: A Study. RIE, Mysore.

Lydia, K. (2001). Virtual Language in Architectural Design. UNITEC, Auckland, New Zealand.

Michael B. (2015). Sustainability: Definition and Five Core Principles. The Sustainability Laboratory Publication. 229 East street, New York.

Nicos, S. (2017). Design for Social Change and Design Education: Social Challenges Versus Teacher-Centred Pedagogies. Design for next. $12^{\text {th }}$ EAD Conference, Saplenza university of Rome.

Noha, H. (2017). Visual Aids and Multimedia in Second Language Acquisition. Published by Canadian Center of Science and Education. English Language Teaching; Vol. 10(6); http://doi.org/10.5539/elt.v10n6p53

Norman, D. A. (1988). The Design of Everyday Things. Published by Basic Books. 250 West 57th Street, 15th Floor, New York, New York 10107. ISBN 978-0-465-05065-9 (pbk.)—ISBN 978-0-465-00394-5

Olabode, E. O., William, S. and Kim, M. (2019). An Assessment of Material Waste Disposal Methods in the Nigerian Construction Industry. Recycling Journal. 4(13). https://doi:10.3390

Oladumiye, E. B. and Adelabu, O.S. (2011). Graphic Design: A Developmental Tool for Eliciting Ethical Values and Human Rights. IRCAB Journal of Science and Technology 1(1)

Ondo State Bureau of Statistics (2019). Retrieved March 5, 2019 from http//www.ondostatistics.org/ondo_profile.php

Otinga C. S. (2014). Media and Environmental Awareness in Kenya: The Case of Tv. A Research Project Presented to University of Nairobi: School of Journalism, as Partial Fulfillment of Degree in Master of Arts (Communication Studies)

Ruksana, S. (2017). Role of Mass Media in Creating Environmental Awareness. National Journal of Multidisciplinary Research and Development. PCSW, SCERT, Assam, India. ISSN: 2455-9040. 2 (1); 0104

Stoknes, P.E. (2015). What we think about when we try not to think about Global Warming. Chelsea Green Publishing, White river junction, Vermont.

Tobias Feldt (2016). Increasing Environmental Awareness Using Comic-Style Illustrations as a Visual Communication Tool, Madagascar. University of Kassel, Germany.tropanimals@uni-kassel.de

Wilson, C. (2010). Arts. Environment. Sustainability. How Can Culture Make a Difference? Heng Mui Keng 
Terrace Singapore 119595: Asia-Europe Foundation (ASEF).

Zeynep, M. A. (2015). Communicating Sustainability with Visuals: Issue Perception and Issue Engagement. LSU Doctoral Dissertations. Louisiana State University and Agricultural and Mechanical College, zaltinay@lsu.edu 